\title{
PRZEGLAD ELERTROTECilillCZIYY
}

Ukazuje się od 1919 roku

$12 ' 13$

Organ Stowarzyszenia Elektryków Polskich - Wydawnictwo SIGMA-NOT Sp. z 0.o.

Fernando P. MARAFÃO', Wesley A. SOUZA' ${ }^{2}$, Eduardo V. LIBERADO ${ }^{2}$, Luiz C.P. da SILVA ${ }^{2}$, Helmo K.M. PAREDES'

UNESP - Univ Estadual Paulista (1), UNICAMP - University of Campinas (2)

\section{Load Analyser using Conservative Power Theory}

\begin{abstract}
This paper deals with the analysis and application of novel conformity factors, defined by means of the Conservative Power Theory (CPT), for the purpose of load analysis and characterization. Basically, such factors are able to describe the influence of different load characteristic on the power factor calculation and they are valid under generic load and supply voltage conditions. Moreover, the development of a flexible smart-meter prototype has been described and used to the experimental validation of all power components and conformity factors considered on the paper.

Streszczenie. $W$ artykule zaprezentowano analizę $i$ zastosowanie nowego współczynnika zgodności zdefiniowanego na podstawie Teorii Zachowania Mocy CPT. Współczynnik zastosowano do analizy obciążeń iich wpływu na współczynnik mocy. Opisano też nową koncepcję miernika typu smart.-meter. Analiza obciążeń przy wykorzystaniu teorii zachowania mocy CPT.
\end{abstract}

Keywords: Conservative Power Theory, Load Analyser, Power Meter, Power Quality, Power Theories, Smart Meter. Słowa kluczowe: Teoria Zachowania Mocy CPT, analiza obciążeń, smart meter.

\section{Introduction}

The growing concern in Power Quality (PQ) area is related to some major topics: the load sensibility, the search for improvements in energy efficiency and consumer awareness, and fault prevention in distribution systems [1]. Therefore, there is a need for relevant $P Q$ indexes and digital monitoring techniques in order to process data and to send information to utilities and/or consumers [2-4].

In this way, traditional meters (e.g., electromechanicals), which inform only kWh to human operator [5, 6], should be replaced by smart meters that may inform several $P Q$ indexes, such as power factor, harmonic distortion, voltage or current unbalances, voltage fluctuation, frequency variation [7] and other relevant information to consumers and utilities, e. g., power components that indicate the predominance of a determined kind of load in a system.

Moreover, it is important that the information would be available at a possible network (websites or applications) [8, 9], which would allow the access of consumers, in order to evaluate their use of energy, as well as utilities, for accountability and revenue metering purposes.

With such motivation, a power meter with wireless communication has been developed considering the possibility of automatic transmission of information to electric utilities or consumers [6,10-12]. Of course, many other different meters can be found on market or on international literature $[3,5,6,10,11,13]$. However, in order to have the required flexibility for implementing the current and power components of the CPT [14-15] and evaluating the performance of the new (load) conformity factors, proposed in [16], the authors were led to develop their own prototype.

The developed power meter calculates the power components and related $\mathrm{PQ}$ indexes based on the CPT, which allow to identify and to quantify the amount of resistive, reactive, unbalance and nonlinear characteristics of a particular load under different supply voltages condition. In fact, as it will be discussed, this is quite different from using traditional $P Q$ indexes, such as: displacement factor, negative and zero sequence factors or total harmonic distortion (THD). Therefore, the major contribution of the paper is related to load analysis by means of the conformity factors recently defined in [16].

\section{CPT - Short Overview}

In order to obtain general power and power factor definitions, which should be valid for linear and nonlinear loads, under balanced or unbalanced configurations, and considering general voltage supply conditions (sinusoidal or not, unbalanced or not, or any combinations), a recent methodology has been proposed by Tenti et al. $[14,15]$. It was called Conservative Power Theory (CPT). This methodology defines conservative electrical quantities, which are obtained by scalar product of voltages and currents and its integrals and derivatives, assuming multiphase circuits that respect Kirchhoff's laws and the theorem of Tellegen [17]

The basic conservative quantities defined by the CPT are the instantaneous active power, which is expressed by the scalar product of instantaneous voltages and currents: (1) $\quad p(t)=\boldsymbol{u} \circ \boldsymbol{i}$

and the instantaneous reactive energy, which is the result of scalar product of unbiased integral of voltages and the instantaneous currents:

(2) $\quad w(t)=\widehat{\boldsymbol{u}} \circ \boldsymbol{i}$

where:

$\boldsymbol{u}$ is a voltage vector that contains phase voltages $\left[\begin{array}{llll}u_{a} & u_{b} & \ldots & u_{m}\end{array}\right]$

$\boldsymbol{i}$ is a current vector containing phase currents $\left[\begin{array}{lll}i_{a} & i_{b} & \ldots\end{array} i_{m}\right]^{T}$;

$\widehat{\boldsymbol{u}}$ is a vector containing unbiased integral of phase voltages $\left[\begin{array}{llll}\hat{u}_{a} \hat{u}_{b} & \cdots & \hat{u}_{m}\end{array}\right]$.

The unbiased phase integral is defined as in (3):

(3) where:

$u_{m}=\int_{0}^{\tau} u(\tau) d \tau$ is the time integral and

$\bar{u}_{m \int}=\frac{1}{T} \int_{0}^{T} u_{m} d t$ is the average value of time integral. 
The average values of (1) and (2) results in the active power $(P)$ and average reactive energy $(W)$, respectively, and they are expressed as in (4) and (5).

$$
\begin{aligned}
& P=\bar{p}=\frac{1}{T} \int_{0}^{T} \boldsymbol{u}(t) \circ \boldsymbol{i}(t) d t \\
& W=\bar{w}=\frac{1}{T} \int_{0}^{T} \widehat{\boldsymbol{u}}(t) \circ \boldsymbol{i}(t) d t
\end{aligned}
$$

\section{A. Current components from CPT}

Based on the conservative quantities defined previously (4 and 5) and as shown in [14, 15], CPT offers a current decomposition in orthogonal components which represent different load characteristics. These components are described as follows:

Active current $\left(i_{a}\right)$ : is the minimum current responsible for active power consumption in each phase of a circuit;

Reactive current $\left(i_{r}\right)$ : is the minimum current responsible for reactive energy flowing in each phase of a circuit;

Void current $\left(i_{v}\right)$ : this current component is neither related to active power nor reactive energy and appears due to nonlinearities between voltages and currents.

These three currents are the basic components and are orthogonal to each other, i.e., the average scalar product among then results zero. Therefore, it is possible to express an equation that relates the RMS values of the current components and the total current, as follows:

$$
\boldsymbol{I}^{2}=\boldsymbol{I}_{a}^{2}+\boldsymbol{I}_{r}^{2}+\boldsymbol{I}_{v}^{2}
$$

In case of poly-phase circuits, with or without return conductor, the active and reactive currents may be decomposed into balanced and unbalanced components, as following:

Balanced active current $\left(i_{a}^{b}\right)$ is the current responsible for the minimum transference of active power from the source to the load. This current is proportional to the voltage and its waveform is in phase with the voltage waveform.

Balanced reactive current $\left(i_{r}^{b}\right)$ is responsible for the minimum reactive energy flowing through the circuit. This current is proportional to the integral function of the voltage.

Unbalance current $\left(\boldsymbol{I}^{u^{2}}=\boldsymbol{I}_{a}^{u^{2}}+\boldsymbol{I}_{r}^{u^{2}}\right)$ is composed by active and reactive components that represent the different values of equivalent conductance and reactivity in each phase.

Using these components in (6), the relation may be expanded to (7):

(7) $\quad \boldsymbol{I}^{2}=\boldsymbol{I}_{a}^{2}+\boldsymbol{I}_{r}^{2}+\boldsymbol{I}_{v}^{2}=\boldsymbol{I}_{a}^{b^{2}}+\boldsymbol{I}_{r}^{b^{2}}+\underbrace{\boldsymbol{I}_{a}^{u^{2}}+\boldsymbol{I}_{r}^{u^{2}}}_{\boldsymbol{I}^{u^{2}}}+\boldsymbol{I}_{v}^{2}$

The terms in (7) are collective values, i.e., each term is calculated by the square root of RMS values from all the phases of the circuit. Furthermore, all components are orthogonal to each other.

\section{B. Power components from CPT}

Each current component previously defined in (7) is associated to a power component through the product of RMS collective values of the correspondent current components and voltage.

Active Power $\left(P=\boldsymbol{U} \boldsymbol{I}_{a}^{b}\right)$ : represents the average consumption of power by the circuit and performs useful work on load, and their value is exactly equal to (4);

Reactive Power $\left(Q=\boldsymbol{U} \boldsymbol{I}_{r}^{b}\right)$ : is a non-conservative term that is related to the phase displacement between voltage and current, which is a characteristic of energy storage elements or electronic loads.

Unbalance Power $\left(N=\boldsymbol{U} \sqrt{\boldsymbol{I}_{a}^{u^{2}}+\boldsymbol{I}_{r}^{u^{2}}}\right)$ : represents the load unbalances;

Distortion (Void) Power $\left(D=\boldsymbol{U} I_{v}\right)$ : is the power due to nonlinear behavior of the load, and it is not related to the useful work or energy storing;
Apparent Power $(A=U I)$ : is the total power of the circuit, which can be calculated by:

(8)

$$
A^{2}=\boldsymbol{U}^{2} \boldsymbol{I}^{2}=P^{2}+Q^{2}+N^{2}+D^{2}
$$

Considering the previous definitions, the authors of the CPT and co-authors have been working on the evaluation of the CPT in several different applications, especially on the control strategies for power conditioning [15, 18-20] and accountability $[14,16,22]$ on the smart grid scenario.

In addition, novel conformity factors were proposed in [16] with the promise of allowing load characterization; however, they were not evaluated in details. So, next section recovers such definitions and Section IV will discuss their application by means of experimental results.

\section{Load conformity factors}

Since the CPT power components can be calculated under distorted and/or unbalanced networks (either in case of fundamental frequency variation), its power components can be very useful to outline performance or conformity factors (indexes) that allow load characterization under different operating conditions. Thus, four possible performance factors are described and discussed in the following.

The distortion (nonlinearity) factor can be calculated by:

$$
\text { (9) } \quad \lambda_{D}=\frac{D}{\sqrt{P^{2}+Q^{2}+N^{2}+D^{2}}}=\frac{D}{A}=\frac{I_{v}}{I}
$$

In terms of load analysis, such factor represents the presence of distortion power (or void current), which does not contribute to active or reactive powers. It is mainly related to voltage and current's nonlinearities, which may increase power losses on the circuit, decreasing its efficiency. Such factor results zero only if $\boldsymbol{I}_{v}=0$, which occurs only in case of linear circuits supplied by sinusoidal voltages.

Considering single-phase or balanced three-phase loads, supplied by sinusoidal voltages, such factor can be associated to the traditional Total Harmonic Distortion $\left(T H D_{I}\right)$ by $\lambda_{D}=\frac{T H D_{I}}{\sqrt{1+T H D_{I}^{2}}}$.

The unbalance factor can be calculated by:

$$
\lambda_{N}=\frac{N}{\sqrt{P^{2}+Q^{2}+N^{2}}}=\frac{\sqrt{I_{a}^{u^{2}}+I_{r}^{u^{2}}}}{\sqrt{I_{a}^{b^{2}}+I_{r}^{b^{2}}+I_{a}^{u^{2}}+I_{r}^{u^{2}}}}
$$

and it indicates possible unbalances on the circuit's equivalent phase impedances (conductances and reactivities). Such factor results zero only if the load is balanced, independently of voltage symmetry or distortion. Of course, in case of single-phase circuits this factor does not matter.

In case of sinusoidal and symmetrical supply voltages, the unbalance factor can also be related to the traditional positive, negative and zero sequence unbalance factors, calculated by means of the Fortescue's transformation on the fundamental current waveforms.

The reactivity factor can be defined as:

$$
\text { (11) } \quad \lambda_{Q}=\frac{Q}{\sqrt{P^{2}+Q^{2}}}=\frac{I_{r}^{b}}{\sqrt{I_{a}^{b^{2}}+I_{r}^{b^{2}}}}
$$

This factor indicates the presence of reactive energy from inductive and capacitive loads, or even from nonlinear loads.

Considering single-phase or balanced three-phase circuits, with sinusoidal supply voltages, the reactivity factor could be calculated directly from $\lambda_{Q}=\sin \emptyset$, being $\varnothing$ the phase angle between any of the phase voltages and currents.

Finally, the general (total) power factor can be calculated as follows:

$$
\lambda=\frac{P}{A}=\frac{I_{a}^{b}}{I}=\sqrt{\left(1-\lambda_{Q}{ }^{2}\right)\left(1-{\lambda_{N}}^{2}\right)\left(1-\lambda_{D}{ }^{2}\right)}
$$


This power factor relates balanced active current to all other current components and equals to unity only if the load is purely resistive and balanced, independently of supply voltages. The presence of any other types of load affects the total power factor. Moreover, a balanced pure resistive load may have unitary power factor even in the presence of non-sinusoidal and/or asymmetrical source voltages.

Considering current operating conditions of distribution systems, this is a much more appropriate definition of power factor, as an efficiency factor, than several others in international standards or literature. Besides, by means of (12) and the previously defined conformity factors, it is also possible to understand the influence of reactive power, load unbalance and nonlinearities, individually, on the power factor value.

Thus, considering these new definitions, it is relevant to mention that a revision of national or international standards might be interesting, especially the definition of boundary values for the power factor, or its traditional interpretation as "inductive" or "capacitive" power factor. In other words, when unbalance and harmonic distortion are taken into account in power systems, the classification of power factor as "capacitive" or "inductive" may became of less relevance.

To avoid possible misunderstanding, it is worth mention that the conformity factors defined in (9-11) are slightly different from those defined in [16]. Here, under ideal conditions, the factors result zero, while in [16] they led to one.

\section{Data Acquisition and Processing System}

In order to design a flexible smart meter prototype, a general purpose data acquisition and processing system has been developed using a DSP and assuming the following main characteristics:

- 12 analog inputs (4 voltages, 4 currents and 4 temperatures);

- 12 bits A/D converter;

- Sampling rate of $6 \mathrm{kHz}$ in each channel (4 times higher than 25th harmonic component of $60 \mathrm{~Hz}$ );

- Nominal voltages: $215 \mathrm{~V}$

- Nominal currents: 35 A;

- Storage time: from 8 hours to 1200 days, depending on the storing interval.

These features have been adopted based on Brazilian standards such as [23]. Details on the implemented data acquisition and transmission system are presented in the following.

\section{A. Data Acquisition}

The general diagram of the data acquisition system is represented on Fig. 1. In order to adjust the measured signals to suitable levels for A/D conversion at the DSP (ezDSP F28335 kit), an electronic circuit was designed for voltage and current measuring and conditioning. Temperatures are also collected for the adjustment of voltage and current inputs.

In this case, four sensors LM35DZ were placed in the prototype, in order to collect the temperatures on different areas inside the meter. The normal operation temperature range was set from $0^{\circ} \mathrm{C}$ to $70^{\circ} \mathrm{C}$. If the temperature is out of range, the device sends an alert signal and turned off. Additionally, knowing that the temperature can influence the accuracy of current and voltage sensors (LA55p and LV25p, respectively), the actual temperature was used to adjust the input measurements. Thus, using the values from the sensor's datasheet, and after some experimental tests under different temperature conditions, the following adjustment (13) has been implemented for input measurements calibration.
(13)

$$
\varepsilon=\left(\varphi_{\text {offset }}+\varphi_{\text {gain }} U_{\text {output }}\right)\left(\theta_{\text {act }}-\theta_{\text {optimum }}\right)
$$

where:

$\varepsilon=$ error to be corrected

$\varphi_{\text {offset }}=$ offset error $\left(1 \mathrm{mVC}^{-1}\right)$

$\varphi_{\text {gain }}=$ gain error $\left(0.05 \% C^{-1}\right)$

$U_{\text {output }}=$ output voltage of the transducer

$\theta_{\text {act }}=$ actual temperature in the sensors

$\theta_{\text {optimum }}=$ optimum temperature $\left(25^{\circ} \mathrm{C}\right)$

Therefore, the maximum error at $0^{\circ} \mathrm{C}$ is $-23.875 \mathrm{mV}$ $(-0.955 \%)$ and the maximum error at $70^{\circ} \mathrm{C}$ is $50.26 \mathrm{mV}$ $(2.02 \%)$, when compared to the measured value.

The error behavior in the sensors is linear (according to the manufacturer's datasheet), so, there is an adjustment signal corresponding to (14).

(14) Signal $_{\text {out }}=\left(0.99045+0.000425 \theta_{\text {act }}\right)$ Signal $_{\text {in }}$

B. Local storage

Regarding to local memory and storage capability, the DSP allows the access to a $4 \mathrm{MB}$ expanded memory called XINTF. Each information package takes about 144 bytes, thus it is possible to estimate the amount of stored information as a function of the sampling time and measuring days, which is described in Table 1.

Table 1 - Estimation of the system's storage capability.

\begin{tabular}{|c|c|}
\hline Sampling time & Estimation of total time of data storage \\
\hline $1 \mathrm{sec}$ & $\approx 8$ hours \\
\hline $1 \mathrm{~min}$ & $\approx 20$ days \\
\hline $30 \mathrm{~min}$ & $\approx 600$ days \\
\hline 1 hour & $\approx 1200$ days \\
\hline
\end{tabular}

For example, if the information packages should be stored every minute, it may be possible to storage 20 days of measurements. Of course, if needed, the system capability could be expanded by adding external memory.

C. Data Transmission

According to Fig. 1, the information processed into the DSP may be stored in an internal memory and thereafter, transmitted using wireless connection through conversion from DSP UART (Universal Asynchronous Receiver and Transmitter) to IEEE $802.11 \mathrm{~b} / \mathrm{g}$.

An UART serial to IEEE $802.11 \mathrm{~b} / \mathrm{g}$ converter was used for wireless communication. Additionally, a communication protocol between DSP and the receiver was designed.

At this point, the complete hardware set may be listed as follows:

- $\pm 5 \mathrm{~V}$ and $\pm 15 \mathrm{~V}$ voltage supply;

- Current conditioning board;

- Voltage conditioning board;

- kit eZdsp F28335;

- UART/IEEE 802.11b/g Linksprite module with antenna Pigtail.

\section{Experimental Results}

In order to validate, experimentally, the previously discussed load conformity factors, for load interpretation and characterization, some different electrical circuits have been considered. The described data acquisition and processing system has been used for voltage and current measurements, as well as for all power and conformity factors calculation.

A. Test circuits

The voltages and currents were measured at the Point of Common Coupling (PCC), as indicated in Fig. 2. Tables 2 and 3 indicate the different supply voltages and load configurations. The supply voltages were adjusted by means of a programmable power source. Except for two cases indicated by "*” in Table 4, most of the analyzed cases were based on three-phase four-wire circuits, with no line impedance. 


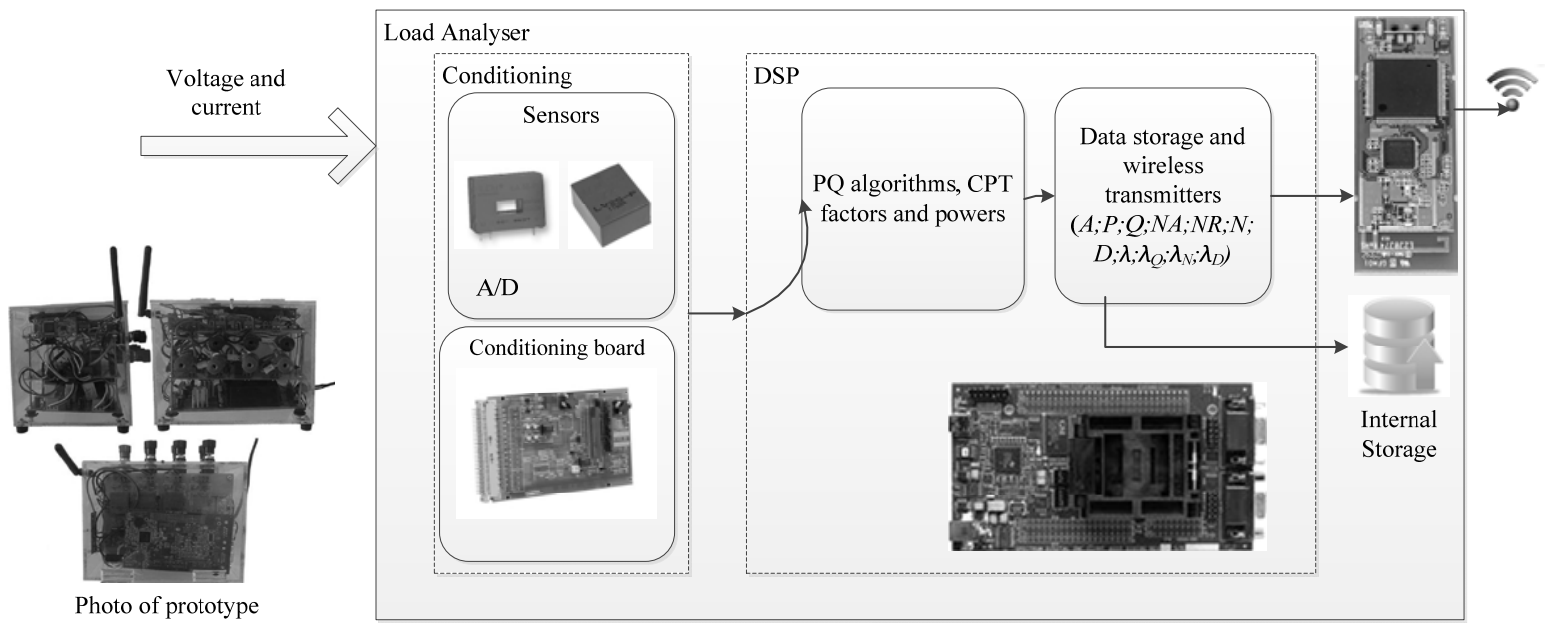

Fig. 1. Block diagram of the data acquisition system.

Table 2 - Different voltage conditions.

\begin{tabular}{|l|l|}
\hline$A$ & Sinusoidal and Symmetrical: $127 \mathrm{~V}_{\mathrm{RMS}}$ each phase \\
\hline B & $\begin{array}{l}\text { Non sinusoidal and Symmetrical: } 127 \mathrm{~V}_{\mathrm{RMS}} \text { plus } 3^{\text {rd }}, 5^{\text {th }}, 7^{\text {th }} \text { and } 9^{\text {th }} \text { harmonics, each with } 5 \% \text { of fundamental } \\
\text { voltage. }\end{array}$ \\
\hline C & $\begin{array}{l}\text { Sinusoidal and Asymmetrical: } U_{a}=127 \mathrm{~V}_{\mathrm{RMS}}, \\
\mathrm{U}_{\mathrm{b}}=113 \mathrm{~V}_{\mathrm{RMS}} \text { and } \mathrm{U}_{\mathrm{c}}=135 \mathrm{~V}_{\mathrm{RMS}}\end{array}$ \\
\hline
\end{tabular}

Table 3 - Different load configurations.

\begin{tabular}{|l|l|l|}
\hline 1 & Balanced resistive: & $\mathrm{R}=8.5 \Omega$ each phase. \\
\hline 2 & Unbalanced resistive: & $\mathrm{Ra}=11.8 \Omega ; \mathrm{Rb}=5.9 \Omega ; \mathrm{RC}=8.5 \Omega$. \\
\hline 3 & Balanced RL: & $\mathrm{R}=8.5 \Omega ; \mathrm{L}=15 \mathrm{mH}$ each phase. \\
\hline 4 & Unbalanced RL: & $\mathrm{Ra}=11.8 \Omega ; \mathrm{Rb}=5.9 \Omega ; \mathrm{RC}=8.5 \Omega ; \mathrm{La}=20 \mathrm{mH} ; \mathrm{Lb}=10 \mathrm{mH} ; \mathrm{LC}=15 \mathrm{mH}$. \\
\hline 5 & $\begin{array}{l}\text { Balanced nonlinear: } \\
\text { (three-phase diode rectifier) }\end{array}$ & $\begin{array}{l}\mathrm{L}_{\mathrm{AC}}=0.5 \mathrm{mH} \text { each phase (inductive input filter); } \\
\mathrm{R}_{\mathrm{DC}}=13.8 \Omega ; \mathrm{C}_{\mathrm{DC}}=2.35 \mathrm{mF} \text { (capacitive output filter). }\end{array}$ \\
\hline 6 & Unbalanced mixed load: & $\begin{array}{l}\mathrm{RaC}=44.4 \Omega ; \mathrm{R}_{\mathrm{RL}}=142.5 \Omega \text { and } \mathrm{L}_{\mathrm{RL}}=61.2 \mathrm{mH} \text { each phase; } \\
\text { three-phase rectifier: } \mathrm{L}_{\mathrm{AC}}=0.5 \mathrm{mH} ; \mathrm{C}_{\mathrm{DC}}=2.35 \mathrm{mF} ; \mathrm{R}_{\mathrm{DC}}=35.2 \Omega .\end{array}$ \\
\hline
\end{tabular}

Table 4 - Power components and conformity factors according to different supply and load conditions.

\begin{tabular}{|l|l|l|l|l|l|l|l|l|l|l|l|l|l|}
\hline & A.1 & A.2 & A.2 & A.3 & A.4 & A.5 & A.6 & B.1 & B.2 & B.2 & B.3 & B.4 & B.5 \\
\hline$A[\mathrm{VA}]$ & 5,848 & 6,239 & 5,781 & 4,812 & 4,927 & 6,942 & 5,038 & 5,746 & 6,321 & 5,925 & 4,773 & 4,965 & 7,022 \\
\hline$P[\mathrm{~W}]$ & 5,849 & 6,009 & 5,617 & 4,011 & 4,099 & 6,112 & 4,026 & 5,746 & 6,085 & 5,815 & 3,965 & 4,075 & 6,045 \\
\hline$Q[\mathrm{VA}]$ & - & - & - & 2,541 & 2,583 & 802.20 & 2,269 & - & - & - & 2,644 & 2,649 & 1,674 \\
\hline$N a[\mathrm{VA}]$ & - & 1,645 & 785.54 & - & 667.34 & - & 565.50 & - & 1,712 & 803.68 & - & 688.49 & - \\
\hline$N r[\mathrm{VA}]$ & - & - & 830.90 & - & 700.79 & - & 595.57 & - & - & 801.63 & - & 690.07 & - \\
\hline$N[\mathrm{VA}]$ & - & 1,645 & 1,144 & - & 983.76 & - & 821.27 & - & 1,712 & 1,135 & - & 974.79 & - \\
\hline$D[\mathrm{VA}]$ & - & - & - & - & - & 3,111 & 1,866 & - & - & - & 263.20 & 274.72 & 3,158 \\
\hline$\lambda$ & 0.997 & 0.966 & 0.978 & 0.830 & 0.827 & 0.883 & 0.803 & 1.000 & 0.963 & 0.981 & 0.831 & 0.821 & 0.861 \\
\hline$\lambda_{Q}$ & - & - & - & 0.534 & 0.530 & 0.177 & 0.481 & - & - & - & 0.555 & 0.545 & 0.267 \\
\hline$\lambda_{N}$ & - & 0.251 & 0.187 & - & 0.189 & - & 0.187 & - & 0.271 & 0.192 & - & 0.197 & - \\
\hline$\lambda_{d}$ & - & - & - & - & - & 0.432 & 0.374 & - & - & - & 0.055 & 0.055 & 0.450 \\
\hline$T H D(\%) V a$ & - & - & - & - & - & - & - & 6.93 & 9.67 & 7.01 & 7.27 & 7.32 & 7.84 \\
\hline$T H D(\%) V b$ & - & - & - & - & - & - & - & 7.09 & 10.11 & 6.98 & 7.39 & 7.57 & 7.55 \\
\hline$T H D(\%) V c$ & - & - & - & - & - & - & - & 7.30 & 9.89 & 7.13 & 7.23 & 7.33 & 7.38 \\
\hline$T H D(\%) I a$ & - & - & - & - & - & 44.17 & 35.77 & 6.98 & 9.35 & 7.01 & 3.89 & 3.14 & 48.92 \\
\hline$T H D(\%) I b$ & - & - & - & - & - & 43.91 & 41.28 & 7.12 & 9.55 & 7.40 & 3.82 & 3.32 & 48.54 \\
\hline$T H D(\%) I c$ & - & - & - & - & - & 44.08 & 43.39 & 6.92 & 9.77 & 6.75 & 3.72 & 2.98 & 48.83 \\
\hline
\end{tabular}

${ }^{*}$ three-phase three-wire circuits, with voltages measured to a virtual star point.

Table 5 - Power components and conformity factors based on sinusoidal and asymmetrical supply voltages.

\begin{tabular}{|c|c|c|c|c|c|c|c|}
\hline & C. 1 & C. 3 & C.5 & $D$ [VA] & - & - & 3,087 \\
\hline$A$ [VA] & 5,651 & 4,648 & 6.776 & $\lambda$ & 0.9997 & 0.8439 & 0.8673 \\
\hline$P[\mathrm{~W}]$ & 5,649 & 3,923 & 5877 & $\lambda_{Q}$ & - & 0.5364 & 0.1612 \\
\hline$Q[\mathrm{VA}]$ & - & 2,493 & 9600 & $\lambda_{N}$ & - & - & 0.1604 \\
\hline $\mathrm{Na}$ [VA] & - & - & 653.1 & $\lambda_{d}$ & - & - & 0.4556 \\
\hline $\mathrm{Nr}[\mathrm{VA}]$ & - & - & 717.0 & $T H D(\%) l a$ & - & - & 44.98 \\
\hline$N[\mathrm{VA}]$ & - & - & 967.68 & $T H D(\%) I b$ & - & - & 56.56 \\
\hline & & & & $T H D(\%) / c$ & - & - & 50.75 \\
\hline
\end{tabular}




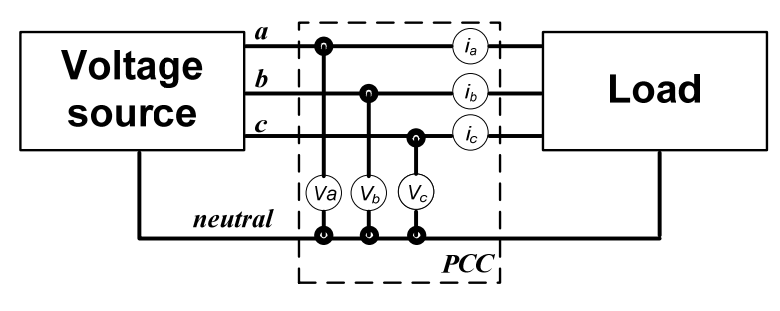

Fig. 2. Diagram of the power circuit configuration.

\section{B. Analyses of the results}

The values of different power components and conformity factors, calculated as discussed in the previous sections, are depicted in Tables 4 and 5 . Dashed cells represent zero or minor values (due to noise in data acquisition or processing - less than $0.1 \%$ regarding to the highest value) of power and factors, which are omitted here in order to facilitate the results interpretation and comparisons.

\section{A.1 and B.1 - Balanced resistive load}

In this circuit, the only power component that results different from zero is the active power. Consequently, the power factor is unitary. In both cases (A.1 and B.1), the phase currents are proportional to the supply voltages, independently of its distortion, thus characterizing a balanced resistive load. However, it is important to notice that even if the voltages and currents are distorted, as in case B.1 $(T H D \neq 0)$, the nonlinearity factor results zero, which is expected for a resistive linear load. Likewise, the unbalance and reactive factors also result zero.

\section{A.2, A.2*, B.2 and B.2* - Unbalanced resistive load}

In these cases, the unbalance factor indicates the behavior of the unbalanced resistive load, and its effect decreasing the power factor. Similarly to the case B.1, the nonlinearity factor results zero in cases B.2 and B.2*, despite of the voltage and current distortions. However, it is quite interesting to observe in cases A.2* and B.2* (threewire circuits), the presence of unbalanced reactive power, which represents the displacement between phase voltages and currents. It happens because, in these cases, the phase voltages are measured to a virtual star point and not any more to the load central point. So, this indicates an unbalanced three-phase three-wire load.

\section{A.3 and B.3 - Balanced RL load}

In this circuit, the reactive power appears due to the inductive load, so the reactivity factor. Consequently, the power factor is reduced to 0.83. In the case of nonsinusoidal voltages (case B.3), the void power component $(D)$ is present due to scattering effects on the inductive load $[15,22]$, which affects the currents and their linearity with respect to the voltages, thus underlining the nonlinearity factor (even if small).

\section{A.4 and B.4 - Unbalanced RL load}

In addition to active power, these cases indicate the presence of unbalance and reactive power components and their respective conformity factors, due to the unbalance $R L$ load. Moreover, void power performs in B.4 likewise in case B.3 and, the power factor is affected by all conformity factors.

\section{A.5 and B.5 - Balanced non-linear load}

In this case, the nonlinearity factor indicates the presence of a non-linear load. Since the three-phase rectifier is balanced, the unbalance factor goes to zero. Thus, just reactivity and nonlinearity affects the total power factor. In case A.5, the nonlinearity factor is entirely accountable to the non-linear load; however, in case B.5 such factor is also affected by the scattering phenomena (distorted voltages), so the resulting values are marginally different.

\section{A.6 - Unbalanced non-linear load}

This case is the most complex in the set of experimental results. The mixed load contains all the characteristics defined by CPT, so all power components and conformity factors are different from zero. Nevertheless, since the voltages are sinusoidal and balanced, each conformity factor expresses a clear load characteristic and its effect on the total power factor

\section{C.1, C.3 and C.5 - Balanced loads (resistive, $R L$ and} nonlinear)

In cases C. 1 and C.3, it is easy to observe that the power components and factors indicate the presence of balanced resistive and RL loads, respectively. In case C.5, however, it is possible to observe how the balanced nonlinear load is affected by the voltage's asymmetry, making much more complex the load interpretation only by means of the applied factors or power components.

\section{Conclusion}

This paper described the development of a flexible smart meter prototype, which has been applied to the evaluation of novel conformity factors, similarly to those proposed in [16]. Detailed discussion of such factors, by means of theoretical analyses and experimental results, has been included.

From the considered cases, it is possible to conclude that the conformity factors correctly describe particular load phenomena or characteristics.

In case of linear resistive load, under distorted supply voltages (B.1 or B.2); even though the current THD is different from zero, the nonlinearity factor $\left(\lambda_{D}\right)$ is null. In case of inductive loads with nonsinusoidal supply voltages, the nonlinearity factor expresses the scattering effect of distorted voltages on the load reactivity (or in this case, reactance). Basically, it represents the differences between voltage and current's waveforms.

Regarding to the unbalance factor $\left(\lambda_{N}\right)$, it is important to observe that it results zero in case of balanced linear loads, even if the supply voltages are asymmetrical. It means that it is not affected by voltage's imperfections, but just by the load behavior.

These conclusions led to the possibility of using such factors for evaluating the power quality on particular loads or installations, instead of the traditional total harmonic distortion, negative and zero sequence indexes. Such conventional quantities are related to the currents' waveforms and not specifically to the load characteristics.

Of course, when supply voltages deterioration and load disturbances are mixed (B.5), it is not so easy to achieve similar conclusions. However, considering the actual power system scenario and foremost discussions and proposals of modern smart grid, we believe that these conformity factors can be very useful in terms of $P Q$ evaluation and possible accountability or revenue metering methodologies.

Future work will deal with detailed association between the CPT conformity factors and traditional $\mathrm{PQ}$ indexes, as well as with the influence of voltage disturbances and line impedance on the load analyses.

The authors wish to express their gratitude to FAPESP (São Paulo Research Foundation, proc. 2009/04918-7 and 2013/08545-6) for supporting this research. 


\section{REFERENCES}

[1] R. C. Dugan, M. F. McGranaghan, S. Santoso and W. H. Beaty, Electrical Power Systems Quality, McGraw-Hill, 2012.

[2] J. de-la-Rosa and A. Moreno-Muñoz, "A web-based distributed measurement system for electrical Power Quality monitoring", IEEE Sensors Applications Symposium (SAS), pp. 206-211, Feb. 2010

[3] B. Byman, T. Yarborough, R. Schnorr Von Carolsfeld and J. Van Gorp, "Using distributed power quality monitoring for better electrical system management", Pulp and Paper Industry Technical Conference, pp. 21-26, Jun. 1998.

[4] A. Ferrero, L. Peretto and R. Sasdelli, "Revenue metering in the presence of distortion and unbalance: myths and reality", IEEE International Conference on Harmonics and Quality of Power Proceedings, pp. 42-47, 14-18 Oct. 1998.

[5] M. Islam, M. Ahmad, M. Islam, A. Mitul, M. Malek and M. Rashid, "Electronic energy meter with remote monitoring and billing system", 7th International Conference on Electrical \& Computer Engineering (ICECE), pp. 240-243, Dec. 2012.

[6] B. S. Koay, S. S. Cheah, Y. H. Sng, P. H. J. Chong, P. Shum, Y. C. Tong, X. Y. Wang, Y. X. Zuo and H. W. Kuek, "Design and implementation of Bluetooth energy meter", Proceedings of the Joint Conference of the 4th International Conference on Information, Communications and Signal Processing and Pacific Rim Conference on Multimedia, pp. 1474-1477, Dec. 2003

[7] P. Lloret, J. Velasquez, L. Molas-Balada, R. Villafafila, A. Sumper and S. Galceran-Arellano, "IEC 61850 as a flexible tool for electrical systems monitoring", 9th International Conference on Electrical Power Quality and Utilisation (EPQU), pp. 1-6, 9-11 Oct. 2007.

[8] A. Pal, C. Bhaumik, J. Skukla and S. Kolay, "Energy Information Gateway for Home", Second International Conference on Intelligent Systems, Modelling and Simulation (ISMS), pp. 235-240, 25-27 Jan. 2011.

[9] GOOGLE, "Google Power Meter: A google.org project", Pilot Program, 2011.

[10] C.-H. Huang, T.-T. Hsien and G.-J. Jong, "Indoor power meter combined wireless sensor network for smart grid application", 8th International Conference on Information Science and Digital Content Technology (ICIDT), pp. 336-339, Jun. 2012.

[11] S.-W. Luan, J.-H. Teng, S.-Y. Chan and L.-C. Hwang, "Development of a smart power meter for AMI based on ZigBee communication", International Conference on Power Electronics and Drive Systems (PEDS), pp. 661-665, 2-5 Nov. 2009.

[12] H. Tan, C. Lee and V. Mok, "Automatic power meter reading system using GSM network", International Power Engineering Conference (IPEC), pp. 465-469, 3-6 Dec. 2007.

[13] P. Ovidiu and C. Gabriel, "DSP's based energy meter", 26th International Spring Seminar on Electronics Technology: Integrated Management of Electronic Materials Production, pp. 235-238, 8-11 May 2003.

[14] P. Tenti, P. Mattavelli and H. K. M. Paredes, "Conservative Power Theory, sequence components and accountability in smart grids", Przeglad Elektrotechniczny, v. 6, p. 30-37, 2010.

[15] P. Tenti, P. Matavelli and H. K. M. Paredes, "Conservative Power Theory, a Framework to Approach Control and Accountability Issues in Smart Microgrids", IEEE Transactions on Power Electronics, pp. 664-673, Mar. 2011.
[16] H. K. M. Paredes, F. P. Marafão, P. Mattavelli and P. Tenti, "Application of Conservative Power Theory to load and line characterization and revenue metering", IEEE International Workshop on Applied Measurements for Power Systems (AMPS), pp. 1-6, Sept. 2012.

[17] P. Penfield, R. Spencer and S. Duinker, "Tellegen's Theorem and Electrical Networks", Cambridge, MA \& London: M.I.T. Press, 1970.

[18] H. K. M. Paredes, A. Costabeber and P. Tenti, "Application of Conservative Power Theory to Cooperative Control of Distributed Compesators in Smart Grids", Przeglad Elektrotechniczny, v. 87, p. 1-7, 2011.

[19] E. V. Liberado, W. A. Souza, H. K. M. Paredes, J. A. Pomilio and F. P. Marafão, "Design of Static VAr Compensator using Reactive Energy," International School on Nonsinusoidal Currents and Compensation, 20-21 Jun. 2013.

[20] H. K. M. Paredes, L. C. P. da Silva, D. I. Brandão and F. P. Marafão, "Possible Shunt Compensation Strategies Based on Conservative Power Theory", Przeglad Elektrotechniczny, v. 87, p. 34-39, 2011.

[21] F. M. Marafão, D. I. Brandão, F. A. S. Gonçalves and H. K. M. Paredes, "Decoupled reference generator for shunt active filters using the conservative power theory," Journal of Control, Automation and Electrical Systems, vol. 24, no. 4, pp. 522534, 2013.

[22] P. Tenti, H. K. M. Paredes, F. Marafão and P. Mattavelli, "Accountability in Smart Microgrids Based on Conservative Power Theory", IEEE Transactions on Instrumentation and Measurement, pp. 3058-3069, Sept 2011.

[23] ANEEL, "Procedimentos de Distribuição de Energia Elétrica no Sistema Elétrico Nacional - PRODIST", Módulos de 1 a 8 , Agência Nacional de Energia Elétrica, 2012 (in Portuguese).

Authors: Fernando Pinhabel Marafão, Univ Estadual Paulista (UNESP), Campus of Sorocaba, Group of Automation and Integrated Systems, (GASI), Av. Três de Março 511, 18087-180, Sorocaba - SP - Brazil, E-mail: fmarafao@sorocaba.unesp.br.

Wesley Angelino de Souza, University of Campinas (UNICAMP), School of Electrical and Computer Engineering (FEEC), Department of Systems of Electrical Energy (DSEE), Av. Albert Einstein 400, 13083-852, Campinas - SP - Brazil, E-mail: wesley@fc.unesp.br.

Eduardo Verri Liberado, University of Campinas (UNICAMP), School of Electrical and Computer Engineering (FEEC), Department of Energy Control and Systems (DSCE), Av. Albert Einstein 400, 13083-852, Campinas - SP - Brazil, E-mail: eduardo.verri.liberado@gmail.com.

Luiz Carlos Pereira da Silva, University of Campinas (UNICAMP), School of Electrical and Computer Engineering (FEEC), Department of Systems of Electrical Energy (DSEE), Av. Albert Einstein 400, 13083-852, Campinas - SP - Brazil, E-mail: lui@dsee.fee.unicamp.br..

Helmo Kelis Morales Paredes, Univ Estadual Paulista (UNESP), Campus of Sorocaba, Group of Automation and Integrated Systems, (GASI), Av. Três de Março 511, 18087-180, Sorocaba SP - Brazil, E-mail: hmorales@sorocaba.unesp.br. 